\title{
Editorial
}

\section{Reputation in financial services}

Reputation management and its close relative issues management have become increasingly significant in financial services marketing over the past decade. The essence of corporate reputation is the image and/or perceptions of the business held by multiple stakeholders. Implicit in this is the impression made by the quality of the company's products and services as well as the impression of the company's behaviour within its communities. These determine the future standing of the company with respect to what it says and does and inform, hopefully, the media who will interpret the company to the outside world. Dowling speaks of the dilution of equity in a company's reputation (brand) that can occur as a consequence of any lapse in standards by the company. ${ }^{1}$ Weerasooria refers to the closure of branches by major banks in Australia in the 1990s as affecting 'the economic and social capital of communities' ${ }^{2}$

In this context this special issue focuses on three distinct areas: first, on the demand side of the business with respect to the consumer decisions about which bank they prefer to have as a partner; secondly, on the supply side, that is the financial institution's own reputation reflected in its internal culture and processes; thirdly, on a neglected stakeholder side, where questions are raised about why banks do not market to their most captive base - their shareholders.

The importance of examining these three aspects is that between them they identify the key elements in the reputation value chain for financial institutions. From the financial services marketing perspective, the focus is more often on the first aspect, the demand side. We seek to show, through the contributions in this issue, that the significance of the other two aspects has at least the same importance and perhaps a more pervasive contribution - than is usually recognised on the reputation of a business.

Financial institutions rely to a greater extent than most other businesses on the trust that customers have that their funds are secure so actual, or perceived, threats to their funds can undermine that trust. No amount of prudential regulation can remedy that. When BCCI closed in Hong Kong after the assurance of the authorities that it was safe for depositors' funds, there was a remarkable run on deposits in all banks, even the two non-issuing banks. While this made no logical sense, it did demonstrate very clearly that consumer trust is a fragile thing that can be easily frightened away.

The contributions in this issue reflect all aspects of corporate reputation.

On the demand side Regan Lam and Suzan Burton contrast the bank selection and share of wallet decisions for small- to medium-sized businesses (SMEs) in Hong Kong and Australia. They also highlight the emphasis on the long-term relationships that are key to Australian consumers and compare this with the bank's willingness to accommodate banking and credit needs, which is attributed more importance in Hong Kong. Christopher Fitzgibbon and Lesley White continue this theme with their exploration of the role of attitudinal 
loyalty in the development of customer relationship management strategy within service firms. The paper from Chris Baumann, Suzan Burton and Greg Elliott further explores loyalty by linking it to share of wallet in retail banking.

The second aspect, the supply side of corporate reputation, is dealt with by Soheila Mirshekary, Ali M. Yaftian and Damien Cross who discuss the impact on the reputation of auditors from their involvement in the HIH collapse and by Rae Weston who examines the National Australia Bank's foreign currency losses in the context of a disaster myopia model. This is also reflected in the contribution of Alex Proimos and Sue Wright who deal with venture capital investment decisions and indicates that information asymmetry is a major risk to the appropriate assessment of proposals.

The third aspect, the neglected stakeholder side, is reflected in Anna Candler's contribution concerning the neglect of bank shareholders as a focus for marketing strategy. As a captive audience receiving regular communications from financial institutions about their shareholdings in them, shareholders seem to offer cheap communication costs and may well exhibit more loyalty than other customers.

We believe it is important that financial services marketing academics and practitioners continue to address these three aspects of corporate reputation.

\section{Rae Weston and Tony Naughton Guest Editors}

\section{ENDNOTE}

This special issue contains selected papers presented at the Emerging Financial Markets and Services Asia-Pacific Conference held in Sydney, 27th-28th May, 2004.

\section{References}

1 Dowling, G. (1994) 'Corporate Reputations: Strategies for Developing the Corporate Brand', Longman, Chesire, Melbourne, Australia, p. 3.

2 Weerasooria, W. (2000) 'Banks and social obligations', Australian Banking and Finance Law Bulletin, Supplement, p. 11 . 